\title{
REVIEW OF CLOUD COMPUTING IN BUSINESS
}

\author{
Dragan S. Marković, Irina Branović, Ranko Popović, \\ Dejan Zivković, Violeta Tomasević \\ Singidunum University, Belgrade
}

\begin{abstract}
:
Cloud computing has been a big IT trend as it offers a solution to the challenges companies face for a long time-rising IT costs, the constant need for capital investments, and increasing energy consumption. Businesses, educational institutions, governments, and individuals are looking at cloud offerings to be able to manage information instead of infrastructure. In this review we look at the phenomenon of cloud computing from the business prospective; we discuss how cloud computing affects industries and enables new business models, what legal issues are yet to be resolved for cloud computing to reach its full potential and how to address possible barriers. Moreover, we present the state-of-the-art in the area of cloud integration in business, and discuss some cutting-edge issues such as energy consumption and carbon emission in energy-efficient load balancing clouds. We conclude with discussion of possible paths the cloud computing will take in years to come.
\end{abstract}

\section{Key words:}

cloud computing, business applications, energy efficiency, load balancing.

This work has been partially supported by the Serbian Ministry of Education and Science (the project III44006).

\section{INTRODUCTION}

Cloud computing is a technology where computing is delivered as a service over the Internet, meaning that data and applications do not need to be located on the user's machine or even on the company's local servers. Instead, data and applications are located on a cloud computing vendor's servers and delivered to the enterprise as required. Also, any staff member is able to access organization's data and applications from any Internet-connected computer. There are numerous benefits of this computing model that include cost efficiency, energy efficiency [15], smaller initial investment, reduced IT resources (hardware, software, human labor), pay-per-use, and focus on business.

Cloud computing has recently received considerable attention in industrial community, driven by idea that users in industry can access cloud computing resources anytime, anywhere, on-demand. It remains a big IT trend, keeping the professional interest high since its beginnings. As a leading part of the information and communication technology, it now has the opportunity to make further significant productivity improvements, helping us transform the world to a more sustainable and more resourceefficient future. Development of cloud technology also calls for regulatory frameworks covering issues such as ownership of personal data, open standards, intellectual property rights, and competitiveness in the market.

For many companies, the cloud computing technology is taking on a new role - as a driver of revenue and enabler of new business models. Inevitably, mobile devices, social networking, cloud computing, and other progressive technologies are profoundly transforming the relationships between businesses and their customers. Industrial society of the past two centuries is shaping into an information society.

The paper is organized as follows. Section II summarizes possible models of implementations of cloud services in business. Section III describes state-of-the-art in the area of cloud integration in business. Section IV is devoted to energy-efficiency of cloud systems. The final section gives some conclusions.

\section{CLOUD BUSINESS MODELS}

Nowadays, cloud computing mainly provides three types of services to clients: Software as a Service (SaaS), Platform as a Service (PaaS), and Infrastructure as a Service (IaaS). At the moment, SaaS is the most popular model [1]. 
Software as a Service (SaaS) refers to on-demand use of the software over the Internet. Applications are provided as a service from the cloud, with end-user licenses procured or "released" in line with changing demand. Businesses are moving steadily towards this model, shifting from licensing software to subscribing to services, typically on per-user, per-month basis. Typically, software that performs a simple task without much need to interact with other systems makes them ideal candidates for SaaS model. Customers who are not inclined to perform software development, but have need of high-powered applications can also benefit from SaaS. Some of typical business applications suitable for SaaS model are: customer resource management, video conferencing, IT service management, accounting, Web analytics, Web content management. SaaS software is natively Web based and aimed at using web tools, like the browser. It was also built with a multitenant back end in mind, which enables multiple customers to use single application. SaaS is not the most appropriate approach in applications where extremely fast processing of real time data is required, applications where legislation or other regulation does not permit data being hosted externally and applications where an existing on-premise solution fulfills all of the organization's needs.

Platform as a Service (PaaS) refers to the tools and environments to build and manage cloud applications and services. PaaS includes platform software services (such as web, application, database servers, enterprise service buses and other middleware, with associated security mechanisms) on which web service-based applications can be built. In PaaS model, the cloud serves as a platform for the creation of software, delivered over the web. PaaS supplies all the resources required to build applications and services completely from the Internet, without having to download or install software. PaaS services include application design, development, testing, deployment, and hosting. PaaS is especially useful in situations where multiple developers are working on a development project or where other external parties need to interact with the development process. Also, it has proven invaluable when companies with existing data sources, for example sales information from a customer relationship management tool, want to create applications which leverage that data. Finally, PaaS is useful for automating testing and deployment services. PaaS may not be ideal in application that must be highly portable in terms of hosting, in cases where proprietary languages or approaches would impact the development process, when proprietary language would hinder later moves to another provider.

Infrastructure as a Service (IaaS) refers to the storage and computing resources as a service, implemented as virtual machine services accessed over the network. It is sometimes also referred to as hardware as a service (HaaS). IaaS cloud model allows renting resources such as server space, network equipment, memory, CPU cycles, and storage space. Conceptually, this model provides a standardized virtual server. The consumer takes responsibility for configuration and operations of the guest operating system, software, and database. IaaS makes sense in the following situations: where demand is very vola- tile, for new organizations without the capital to invest in hardware, where the organization is growing rapidly and scaling hardware would be problematic, where there is pressure on the organization to limit capital expenditure and to move to operating expenditure, for specific line of business, trial or temporary infrastructural needs. Examples of situations where caution with regards IaaS is advised include: when regulatory compliance makes the offshoring or outsourcing of data storage and processing difficult, when the highest levels of performance are required, and on premise or dedicated hosted infrastructure has the capacity to meet the business needs.

Cloud computing represents a set of approaches that enable organizations to engage quickly and effectively, and free up resources in real-time. While cloud computing makes sense for some areas of company business, it usually cannot be applied across all of company IT infrastructure. Managers and IT executives need to take a closer look at their specific business needs, coupled with their existing IT infrastructure and make an assessment about what makes sense for the company. For each application or business service, it is always necessary to create a business case that evaluates and justifies migration to the cloud, and then to review it throughout the lifetime of the service. Taking into account existing cloud services, some new business models are proposed such as Cloud Business Model Framework (CBMF) and Cloud Cube Model (CCM).

Weihardt et al. proposed a holistic business model framework [2]. CBMF is mainly categorized in three layers, analogously to the technical layers in Cloud services, such as the IaaS, PaaS and SaaS application layer on top. In CBMF model, the infrastructure layer comprehends business lifecycle from development to productive provisioning, while the application layer is what most people get to know from cloud computing as it represents the actual interface for the customer.

CCM proposed by The Jericho Forum (JF) is used to enable secure collaboration in the appropriate cloud formations best suited to the business needs [3]. The JF points out that many cloud service providers claim themselves to be able to deliver solutions, so cloud customers need selecting the right formation within CCM suiting their needs. Within CCM, four distinct dimensions are identified. They are: External and Internal (Internal means private clouds, and External means public clouds), Proprietary and Open (Proprietary means paid services or contractors, and Open stands for open source services or solutions), Perimeterized and De-Perimeterized (Perimeterized means IaaS or Paas, while De-Perimeterized means SaaS) and Insourced and Outsourced (Insourced means in-house development of clouds, and Outsourced refers to letting contractors or service providers handle all requests; most of cloud business models fall into this category).

\section{CLOUD INTEGRATION IN BUSINESS}

Businesses, educational institutions, governments, community organizations, and individuals are looking at 
cloud offerings to be able to focus on managing information instead of infrastructure. There are various guides, reports and success examples about cloud adoption and integration in the business world [4], [5], [6]. Every type of business can benefit from cloud technology; however, the usage differs depending on respective business models. In the following, we present insights on some typical cases in which cloud hosting platform has been adopted.

Healthcare is in a period of accelerating change that requires continual innovation. Healthcare economics, emerging care and business models aligned with personal values and well-being are signaling a major shift in how healthcare organizations will compete and operate in the years ahead [6]. The most important advantages of cloud computing in healthcare include reduced costs, location independence, and better information management. Cloud-based billing and consumer-oriented management applications provide a better access to healthcare and data, especially in the remote areas. Also, the use of electronic health records and exchanging information across providers are notable benefits. Many countries are establishing cloud health information exchanges, where information can be easily shared between hospitals, health systems, physicians, and clinics. Although data privacy, security and safety policies are still obstacles for embracing cloud computing, the cloud healthcare has a potential to make healthcare records of people globally available for easy access and sharing. According to a report [7], globally $32 \%$ of the healthcare facilities are already using cloud applications and close to $75 \%$ of the organizations - which are not using any cloud applications - are considering adopting it in the next three to five years.

Cloud applications will enable the educational system to leverage the efficiency across the nations and to create a setup where students will be able to attend the classes irrespective of the geographical location. Many universities have already started to offer virtual tuitions to students located at distant places. As the number of cloud applications widens, an improved collaboration will be possible that will further enhance knowledge sharing, and people will be able to access the latest technologies at an affordable price. Using the power of cloud computing, Cisco Networking Academy now connects a community of 20,000 ICT educators dedicated to preparing students to become skilled professionals [8]. A large effect of cloud computing can be seen in science. As pointed out in [9], in any engineering lab today, instead of clumsy equipment specific to the lab's specialty, one is more likely to find racks of computers since the complexity of today's scientific and engineering problems is far beyond the capabilities of traditional tools. Research is based on modeling and simulation that require massive amounts of computing power, and cloud computing provides ready access to it on a highly efficient pay-as-you-go basis. Cloud computing is advancing scientific progress in another way. While previously only the largest companies could afford their own massive computer clusters, immense processing performance is now within reach for any small research team or a group of individuals. In a sense, cloud computing democratizes computing power, giving researchers novel opportunities to "big science". Typical advantages of cloud computing such as scalability and the possibility to create easy-to-use platforms are useful also for educational settings. Innovative teaching tools and reference materials allow educators to make the subject matter more interesting to the "visual generation" of their students.

Governments around the world are seeking to digitize their economies to connect all members of society through access to - and sharing of - digital content via the Internet from anyplace at anytime to work, play, consume and learn. Government at all levels is looking for ways to improve services and justify budgets. One of the prominent aspects generally associated with government bureaucracy is large paper trails. Currently there is a trend where government establishments are making a fast move towards utilizing the cloud technology for safeguarding their networks and enabling faster transactions. Using the cloud technology, governments can streamline all the operations and significantly decrease the infamous huge amount of paper trails. This will not only save the money and trees, but will also contribute to the reduction of energy consumption and enable better transparency and collaboration. Upgrading to the cloud technology will help the government bodies with providing better services to the people and with better handling of the safety and privacy regulations. Despite the steadfast progress in cloud adoption, cloud security remains a hot topic. Some surveys show that up to $70 \%$ of government employees have concerns about the cloud security and compliance [10]. Cloud solutions must offer customers a peace of mind that citizens' data is safe in the cloud. Perceived security vulnerability is still the number one concern with the cloud and a major impediment to wider and faster cloud adoption in governments.

Many large hotels have moved to cloud computing to get closer to customers. From reservation systems to menus, everything is available across the continents without any extra cost in infrastructure and individual training resources at every location. With cloud hosting services people will be able to simplify tasks like booking a room, apartment, restaurants and motels. With further improvisation in cloud technology, people will also be able to record these transactions directly to the company's payment systems. Everything would be served through the handheld devices in constant sync with the cloud platforms.

With the appearance of Apple and Android technologies, people have started listening to music through the $3 \mathrm{G}$ networks as well. In the current scenario people can easily utilize any music service, select the songs they want and listen to them from anywhere in the world; all this is possible as a result of cloud computing services. Thus, the cloud technology is beneficial for both listeners (as they can listen to their favorite songs anywhere at any time) and for the musicians as well (as their compositions reach out to people through a fast and efficient medium). The cloud computing benefits are especially timely for the broadcast media industry as it embraces the concept of 'TV Everywhere' at the same time as it moves to IP networks for transmission. These two trends fit well together as broadcasting migrates from dedicated (and largely 
proprietary) infrastructures to IT-based platforms better suited to delivering video to a vast array of devices, rather than just conventional TV sets. This, though, brings challenges: the devices come in all shapes and forms, which increases the complexity of delivering a format at sufficient quality and without consuming an unnecessary amount of bandwidth [11]. Various categories of providers are interested in the cloud as a vehicle for reaching as many people as possible, but there are some conflicts of interest. Content owners holding the rights to broadcasts are anxious to avoid the cloud breaking existing agreements. Traditionally, rights to premium content such as movies and sport have been broken down into geographical silos often defined by country or even regions, as has happened in the US. This can inhibit cloud distribution of video content but it is also an opportunity - the cloud itself can become the 'place' where digital rights are negotiated and applied.

Accounting firms deal with data day in and day out. The volume of numbers that go through an accounting office each day is unimaginable. Taking business to the cloud allows accountants to work from anywhere, at any time. It is a way to reduce costs, improve efficiency and make data more accessible. Most customers prefer communicating with their accountant via the Internet, and in many ways, the new cloud-based dashboards, reporting applications and unified communications systems that are now available only make this easier. By enabling better collaboration and communication among geographically diverse staff and clients, accounting firms' processes and workflows are vastly improved and the work gets done much faster - often with greatly reduced travel costs [12].

Manufacturing industry may also be a great beneficiary of the cloud computing. For example, the manufacturers can implement large internet virtual server farms for facilitating better management of the business and manufacturing setup. Moreover, with the use of SaaS, Paas and IaaS, the manufacturers can establish a virtual presence from any location around the world. Using cloud computing, they can also connect plants to an IT infrastructure and more easily find new business opportunities.

Tourism is another industry that is increasingly affected by cloud computing. The "consumerization" of computing technology is changing the way travelers interact, obtain information and purchase travel needs. They are becoming increasingly informed, empowered and demanding. They are asking for differentiated experiences, and, indeed, if companies in this business do not take this to heart, they stand to lose share-of-wallet. As a result, new nimble business approaches are needed to sustain market share. Travelers need to be able to share their experiences with their social networks, make new arrangements in real time and add new services to their itineraries [13]. To support new business approaches and seamless travel experiences, a modern, flexible and scalable approach to applications and infrastructure must be adopted. The current distribution networks are not agile enough to address demands from technology empowered travelers. In addition, changing business processes and the empowered traveler have driven transaction volumes and system loads to new levels never envisioned by the distri- bution companies. Cloud computing offers new and flexible ways to provision resources, as well as to build and deploy new updated and modernized applications.

The cloud computing service model is a sound business model from both provider's and customer's perspectives. Providers invest in the necessary infrastructure and management, and in return receive a regular income stream from the investment by means of service subscriptions. Since at any given time substantial numbers of customers are inactive, the provider reaps the benefits of the economies of scale and can charge lower subscription fees. The customers in turn see convenience benefits from having data and services available from any location, from having data backups centrally managed, from the availability of increased capacity when needed, and from usage-based charging.

Commoditization usually takes some time to develop in industries, but in some aspects of cloud it is happening rather quickly. Recent IDC research shows that worldwide revenue from public IT cloud services exceeded $\$ 21.5$ billion in 2010 and will reach $\$ 72.9$ billion in 2015, representing a compound annual growth rate of nearly $30 \%$ [14]. This rapid growth rate is over four times the projected growth for the worldwide IT market as a whole (6.7\%). By 2015, one of every seven dollars spent on packaged software, server, and storage offerings will be through the public cloud model.

\section{CLOUD AND ENERGY EFFICIENCY}

There is no consensus on whether cloud computing is a more energy-efficient choice in general compared to running in-house IT operations [15]. Some sources claim that among other benefits, cloud computing delivers multiple efficiencies and economies of scale, which contribute to the reduction of energy consumption per unit of work.

Others however have found that cloud computing is not always the most energy efficient computing option, and under some circumstances can be even more energy intensive than traditional in-office computing. For example, one scenario when cloud computing may consume more energy than conventional computing is when companies use cloud computing for storing data and when the number of downloaded and accessed files becomes larger.

Techniques like load balancing are current areas of analysis in order to achieve more "green" computation. Namely, load balancing is a technique of distributing the dynamic workload across multiple nodes to ensure that no single node is overloaded. In essence, load balancing techniques help in optimal utilization of resources and thus minimize the resource consumption, which further reduces energy consumption. Load balancing is done so that every virtual machine in the cloud system does the same amount of work, therefore increasing the throughput and minimizing the response time.

In any case, energy consumption of the cloud computers should be controlled in order to optimize the energy consumption for a specific computing effort. This requires a good architectural design that could be tailored 
using efficient algorithms to address not only power consumption but also network performance and cost. More research efforts are required to design energy aware routing algorithms capable of consolidation of workload on group of servers. Also, new algorithms empowering the energy-aware middleware should be driven by smart heuristics that always take into account the trade-off between performance and energy savings.

\section{CONCLUSION}

Cloud computing has reached maturity and many businesses are investing in it. The business benefits of cloud computing are extensive and are not limited to the IT department, but affect the entire enterprise.

Cloud computing cannot be sufficiently understood as a standalone phenomenon in the IT market, but rather as a core ingredient of a larger transformation of the IT industry - and many other industries using IT to transform themselves. Other ingredients enabled by the cloud - and, in turn, accelerating the cloud adoption - include the expanding "species" of mobile devices, the explosion of mobile apps, the growing availability of wireless broadband, and the explosion of big data tools. Cloud computing now has the opportunity to help transform the world to a more sustainable, lower carbon and more resourceefficient future.

In this paper we have reviewed how notable benefits of the cloud computing model (reduced costs, economies of scale, flexibility, and highly reliable services) can help different businesses. This certainly implies that further development of cloud computing will promote economic growth, increase productivity, and shift the type of jobs and skills required by businesses.

\section{REFERENCES}

[1] "What Cloud Computing means for business, and how to capitalize on it”, Deloitte, 2010.

[2] C. Weinhardt, A. Anandasivam, B. Blau, N. Borissov, T. Meinl, W. Michalk, and J. Stößer, "Cloud computing - a classification, business models, and research directions," Business \& Information Systems Engineering (BISE), vol. 1, no. 5, pp. 391-399, 2009.
[3] Jericho Forum, "Cloud Cube Model: Selecting Cloud Formations for Secure Collaboration Version 1.0", Jericho Forum Specification, 2009.

[4] “The power of Cloud”, IBM Executive Report, 2012.

[5] The Benefits of Cloud Computing, Whitepaper, LocaLoop, 2013.

[6] IBM, Cloud Computing: Building a New Foundation for Healthcare, available online at http://www-05.ibm.com/de/ healthcare/literature/cloud-new-foundation-for-hv.pdf.

[7] Healthcare Cloud Computing (Clinical, EMR, SaaS, Private, Public, Hybrid) Market - Global Trends, Challenges, Opportunities \& Forecasts $(2012$ - 2017), available online at http://www.marketsandmarkets.com/Market-Reports/ cloud-computing-healthcare-market-347.html.

[8] Cloud Computing Delivers Education to Millions, available online at http://www.cisco.com/web/learning/netacad/ WLC/pdf/NetAcad_Cloud_CS.pdf.

[9] J. McEleney, The cloud's impact on society, available online at http://www.connect-world.com/ cwiml/index.php/ magazine/global-ict/item/14040-the-cloud's-impact-onsociety, 2011.

[10] Pega Cloud for Government: Security \& Reliability for Government Agencies, Pegasystems Inc. , available online at http://www.pega.com/sites/default/files/private/PegaCloud-for-Government-Security-And-Reliability-WhitePaper-Feb2012.pdf, 2012.

[11] P. Hunter, Cloud computing benefits for broadcast media industry, available online at http://eandt.theiet.org/magazine/2012/05/clouds-broadcast-benefits.cfm, 2012.

[12] J. Uglietta, Cloud Computing Benefits for Accounting Firms, available online at http://www.aisn.net/index. php/2012/08/cloud-computing-benefits-for-accountingfirms/, 2012.

[13] IBM, Cloud Computing for the Travel and Transportation Industry, 2012.

[14] Budget 2013, available online at http://www.ey.com/Publication/vwLUAssets/EY-Analysis-Budget_2013/\$FILE/ EY-Analysis-Budget_2013.pdf.

[15] D. Zivkovic, D. Markovic, Energy efficiency of cloud computing, 10th International Scientific Meeting SINERGIJA 2012, pp. 126-130, Bijeljina, BIH, 2012. 